\title{
REPOSICIONANDO O DEBATE DA FRONTEIRA PARA PENSAR A EXPROPRIAÇÃO E A VIOLÊNCIA NA AMAZÔNIA HOJE
}

\author{
Laura dos Santos Rougemont \\ Doutora em Geografia, Universidade Federal Fluminense (UFF), Niterói, RJ, Brasil \\ Núcleo de Estudos sobre Território, Ações Coletivas e Justiça (NETAJ) \\ Isrougemont@gmail.com
}

\begin{abstract}
RESUMO
O presente trabalho tem como objetivo realizar uma releitura acerca da noção de fronteira, tomando-a como ponto de partida para refletir a conflitualidade presente na região da Amazônia Legal. Parte-se da hipótese de que as políticas territoriais sobre a fronteira amazônica carregaram, historicamente, uma ideologia do progresso e da modernidade como parte da ação do Estado, o que vem contribuindo para a ocorrência de um grande número de conflitos envolvendo terra e território na Amazônia. Para isso, serão apresentadas algumas interpretações acerca da fronteira e da sua relação com a construção da nação e do progresso. Tal discussão é recolocada para compreender tanto o histórico, como também o atual momento de exploração da Amazônia. A análise utiliza-se dos dados da violência no campo registrados pela Comissão Pastoral da Terra (CPT), referentes à última década, bem como de uma revisão bibliográfica sobre o tema, além de reportagens e levantamentos feitos por mídias alternativas com enfoque na questão agrária. Conclui-se que a expansão de projetos sobre as fronteiras amazônicas faz parte de um movimento contínuo de acumulação e expropriação, permitindo estabelecer nexos entre a dinâmica de fronteira e o aumento da violência na região.
\end{abstract}

Palavras-chave: Modernização. Estado. Integração. Regimes de desapropriação. Assassinatos.

\section{REPOSITIONING THE FRONTIER DEBATE TO THINK ABOUT EXPROPRIATION AND VIOLENCE IN THE AMAZONIA NOWADAYS}

\begin{abstract}
The present work aims to re-read the notion of frontier, taking it as a starting point to reflect the conflict present in the Legal Amazon region. It is assumed that the territorial policies on the Amazonian border have historically carried an ideology of progress and modernity as part of the State's action, which has contributed to the occurrence of a large number of conflicts involving land and territory in the Amazon. For that, some interpretations about the border and its relationship with nation building and progress will be presented. Such discussion is replaced to understand both the history, as well as the current moment of exploration of the Amazon. The analysis uses data on violence in the countryside recorded by "Comissão Pastoral da Terra" (CPT), for the last decade, as well as a bibliographic review about the subject, in addition to reports and surveys carried out by alternative media focusing on the agrarian issue. It is concluded that the expansion of projects on the Amazonian borders is part of a continuous movement of accumulation and expropriation, allowing the establishment of links between the dynamics of frontiers and the increase of violence in the region.
\end{abstract}

Keywords: Modernization. State. Integration. Expropriation regimes. Murders.

\section{INTRODUÇÃO}

Os debates em torno da noção de "fronteira" foram e são realizados em diversas áreas das Ciências Sociais e Humanas, tendo como destaque os estudos na Antropologia, na Sociologia, nas Ciências Políticas, na Economia, na História, na Literatura e na Comunicação Social - nestas duas últimas a partir de romances e ensaios escritos por literatos e jornalistas. A fronteira é também objeto de debate do qual se ocupa a Geografia. Apenas para situar alguns trabalhos, destacam-se aqueles realizados por Zusman (1999); Cataia (2007); Nogueira (2007); Cardin (2011); Arriaga Rodríguez (2012); Ferrari (2014) e Benedetti (2018). Esta diversidade de trabalhos aponta tanto para a perspectiva dos estudos com enfoque geopolítico, quanto para estudos de Geografia da População (com enfoque sobre o tema das Migrações), da Geografia do Trabalho (em se tratando da precarização do trabalho na fronteira), ou, por exemplo, da Geografia Cultural (nos debates em torno da construção de identidades) - isto apenas para situar alguns casos. Certo é que, independentemente do foco de

$\begin{array}{lllll}\text { Caminhos de Geografia Uberlândia-MG } & \text { v. 23, n. } 85 & \text { fev./2022 } & \text { p. 315-329 Página } 315\end{array}$


análise de cada um destes campos, a fronteira tem sido uma questão-chave da leitura da formação histórica e geográfica, permitindo analisar desdobramentos econômicos, sociais, jurídicos, ambientais, agrários e outros.

Neste sentido, observar os fenômenos que ocorrem em áreas de fronteira pode contribuir para uma potente análise dos processos da transformação socioespacial, tanto da perspectiva das fronteiras administrativas (internas e externas), quanto das fronteiras como áreas de expansão capitalista, as quais passam a ser incorporadas pelo estado e pelos agentes privados. Aqui, em específico, será privilegiada a discussão relativa à segunda abordagem, ou seja, da fronteira como sinônimo de uma dinâmica que promove o esgarçamento de uma frente de expansão (o frontier). O objetivo é abordar de que forma a problematização da fronteira - ou mesmo de uma ideia traduzida como "fronteira" tem contribuído para a própria materialização de projetos de incorporação e "desenvolvimento" econômico sobre o espaço agrário brasileiro e, em especial, sobre a Amazônia Legal. E, principalmente, como a sucessão destas frentes tem acirrado os conflitos no campo, gerando múltiplas violências.

Parte-se da premissa de que a fronteira é um instrumento de análise do espaço e, consequentemente, de percepção das disputas de poder que se travam nos territórios com lógicas diversas e adversas. Isso indica que mais do que um retrato da consolidação de algum projeto bem definido e delimitado, a fronteira representa um processo em construção, incompleto, o qual pode revelar a latência de novas dinâmicas socioespaciais e econômicas em curso e, por sua vez, de conflitos e violência. Por esta razão, trata-se de investigar as fronteiras como um momento ou uma situação em que está ocorrendo um ajuste espacial.

O presente trabalho tem como objetivo realizar uma releitura acerca da noção de fronteira, tomando-a como ponto de partida para refletir a conflitualidade presente na região da Amazônia Legal. A principal hipótese é que as políticas territoriais sobre a fronteira amazônica carregaram, historicamente, uma ideologia do progresso e da modernidade como parte da ação do Estado, o que vem contribuindo para a ocorrência de um grande número de conflitos envolvendo terra e território na Amazônia. Estas políticas de estado voltadas para a região exprimem, por meio de projetos de expansão em novas fronteiras do capital, a recorrência do colonialismo interno e da colonialidade do poder - nos termos debatidos por Stavenhagen (1963); Cardoso de Oliveira (1966); Casanova (2006) e Rivera Cusicanqui (2010). Neste sentido, pretende-se estabelecer nexos entre tais políticas e a alta conflitividade no espaço agrário amazônico.

A noção de fronteira é recolocada para compreender tanto o histórico, como também o atual momento de exploração da Amazônia Legal, correlacionando este processo de expansão aos dados da violência no campo, especialmente aqueles registrados nos cadernos de conflitos da Comissão Pastoral da Terra (CPT), referentes aos anos de 2009 a 2018. Também foi realizada uma revisão bibliográfica sobre o tema, bem como análise de reportagens e levantamentos feitos por mídias alternativas com enfoque na questão agrária.

\section{UMA PRIMEIRA NOTA SOBRE A FRONTEIRA}

A definição mais convencional do que se entende por fronteira está associada à ideia de "divisão" ou "separação". Como pontua Ferrari (2014), o termo fronteira é utilizado para uma diversidade de sentidos, associando-se tanto a fronteiras materiais quanto metafóricas. É empregado para indicar a linha divisória entre duas sedes político-territoriais, como países, estados ou municípios, mas também em sentidos simbólicos ou figurados: fronteira social, fronteira moral, fronteira linguística, fronteira militar etc. De qualquer maneira, merece atenção o fato de que "o uso do termo parece sugerir duas realidades opostas, qualquer que seja a natureza dessas realidades" (FERRARI, 2014, p.2).

O geógrafo e historiador Hervé Théry (2015) indica que o primeiro sentido geral da fronteira na Geografia é enquanto fronteira política que, grosso modo, é a linha que separa dois países. A fronteira política se delimita, historicamente, em torno da militarização das zonas fronteiriças, com forte agenciamento de forças de segurança nacional, como o exército, a marinha e a aeronáutica, bem como com a instalação de fortalezas como marcas da delimitação do poder no espaço. A transposição destas fronteiras, em geral, sem autorização do estado, corresponde à execução de um delito, de um crime.

Não é toda fronteira que se pode cruzar facilmente, visto que algumas se constituem como zonas mais arriscadas do que outras. Alguns grupos ou indivíduos apelam para a liberalização das fronteiras

$\begin{array}{lllll}\text { Caminhos de Geografia } & \text { Uberlândia-MG } & \text { v. 23, n. } 85 & \text { fev./2022 } & \text { p. 315-329 Página } 316\end{array}$


em determinados sentidos, reivindicando não só o direito de circular por elas, mas também o direito de circular informação ou ajuda humanitária. Como exemplo, temos organizações como os "Médicos sem Fronteiras" e outros profissionais, como advogados, engenheiros ou esportistas. Estes coletivos evocam o direito de intervir em países com surtos de doenças ou vítimas de catástrofes naturais, tendendo a uma negação política da fronteira, pelo direito de ser "cidadão do mundo". O movimento de refugiados na fronteira põe em xeque os limites desta transposição, transnacionalizando questões muito delicadas por quais passam determinadas populações em seus países, se obrigando a evadirem na fuga de guerras ou em decorrência de calamidades de cunho ambiental, como é o caso dos "refugiados climáticos" (THÉRY, 2015).

Hervé Théry (2015), no entanto, faz uma distinção sobre a ideia de fronteira como limite político ("boundary") e a fronteira como frente ("frontier"). Enquanto a primeira proposta é amparada por leis, convenções e tratados que definem os limites regulatórios entre países, estados ou municípios, dando conta de uma perspectiva político-administrativa acerca de seu significado, a segunda referese aos ciclos de expansão associados ao avanço de frentes agrícolas, frentes pioneiras e/ou frentes de expansão. Ele destaca que junto com a frontier, além de aspectos econômicos, estão associados elementos com forte caráter social, como os relacionados à história, à cultura, às identidades, em suma, à construção de um tipo de sociedade, com suas maneiras próprias de funcionamento.

Segundo Théry (2015), a frontier americana, que estava aberta desde o século XVII, foi oficialmente fechada em 1912, com o loteamento do estado de Arkansas, no sudeste do país, tratando-se hoje de um fato histórico. Concomitantemente ao movimento da fronteira foi se forjando uma mentalidade pioneira que esteve associada às ideias de independência, liberdade, mas também de violência nos EUA.

Já no Brasil, a fronteira não está fechada completamente, dado o grau de imaturidade de certas formações socioespaciais, especialmente urbanas, mas também devido à intermitência de ocupação de determinados territórios, notadamente no centro-oeste e na Amazônia. Para ele, a fronteira aberta no Brasil ainda é uma realidade e as ondas de avanço a partir de frentes de expansão ainda permanecem, deixando seus rastros no território e implicando na construção de subjetividades nacionais (THERY, 2005).

Tal panorama coincide com a interpretação de Martins (1996), a partir de Zusman (1999), para quem a teoria da fronteira pode ser compreendida como um desdobramento da teoria da expansão territorial do capital. Dado que a expansão territorial do capital é conflitiva, ela põe em jogo questões como a propriedade da terra e pondera também sobre a sobrevivência de diferentes setores sociais.

A geógrafa Bertha Becker (1984) assinala que a fronteira é o espaço de incorporação à cadeia global e fragmentada da divisão territorial do trabalho, de modo que o Estado se empenha para estruturá-la e integrá-la, ao mesmo tempo em que manipula a preservação da imagem de "espaço alternativo" na dimensão ideológica. Auxiliando na viabilização da ocupação de áreas novas, o Estado sempre atuou na reprodução combinada do latifúndio e do campesinato (BECKER, 1984; 1988).

Assim, a fronteira orienta-se neste artigo pelo seu significado e sinônimo de "terra livre", ou seja, de espaços ainda não plenamente ocupados pelo capital.

\section{O MITO DA FRONTEIRA E SEU PAPEL NA CONSTRUÇÃO DA NAÇÃO E DO OUTRO}

Há muito que a fronteira vem sendo objeto de estudo de uma miríade de intelectuais e/ou campos de conhecimento. Não só da fronteira como uma ideia - ou, mais precisamente, como um mito - mas também das práticas e ocorrências em áreas de fronteiras. Um dos mais renomados estudiosos da fronteira foi Frederick Turner (1996), norte-americano que discutiu a problemática do mito da fronteira para explicar o desenvolvimento da nação estadunidense. Para Turner, foi o avanço sobre terras livres no Grande Oeste que explicou o desenvolvimento dos EUA. Além disso, foi o fator que conformou as instituições políticas, o nacionalismo ou a redução dos localismos, do individualismo e da competição pelos recursos abundantes (terras). Todos estes aspectos, tidos como positivos para a construção da nação, propiciaram o direcionamento a uma democracia cada vez mais radical naquele país.

Cabe apontar para a compreensão, já em Turner (1996), da fronteira como algo dinâmico, em constante movimento, sendo a mobilidade uma das tônicas de sua análise. Pode-se induzir daí que a fronteira também aparece sob um forte aspecto situacional, ou seja, de transição para algo novo, para uma situação diferente da anterior, de travessia entre espaços-tempos distintos. Por isso, para

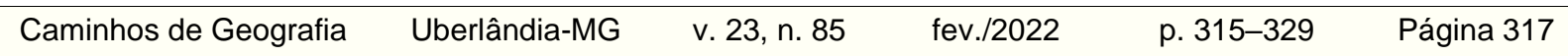


Turner, a fronteira é uma linha que separa a terra povoada da terra livre e também o ponto de encontro entre civilizado e primitivo. Em outras palavras, o ponto que separa o deserto e o selvagem (wilderness) das novas oportunidades de terras, local onde os pioneiros tendem, continuamente, a evoluir rumo à civilização e a uma nova nação, num movimento de renovação e progresso contínuos (TURNER, 1996; VELHO, 1979; WEGNER, 2009).

No Brasil, é notória a influência das ideias de Turner no período republicano, especialmente no Primeiro Governo Vargas, durante o Estado Novo (1937-1945), quando houve maior apelo da ocupação do "oeste" do país a partir da criação do programa "Marcha para o Oeste". De modo semelhante ao que ocorrera nos EUA, a fronteira no Brasil e a conquista do Oeste passaram a ser elementos centrais na literatura nacionalista e, por sua vez, no processo de formação da nação brasileira, segundo aponta Fernandes (2006). Entre a elite letrada foi disseminada a ideia de que o povo brasileiro seria forjado por uma união entre o litoral (mais desenvolvido) e o interior (visto como mais atrasado). A reprodução destas ideias contribuiu para a construção de uma identidade nacional e, consequentemente, de certa mitificação em torno de áreas de fronteira interna.

Faulhaber (2001) explica que, no caso brasileiro, as ideias de Cassiano Ricardo tiveram bastante influência para a criação do "mito da fronteira", entre os anos 1930 e 1940, tendo sido ele um dos pioneiros na adoção da teoria de Turner no país. Em Ricardo, o mito da fronteira aparece como responsável por legitimar, a partir do discurso sobre a integração nacional, uma ordem política autoritária que tem sua origem no Estado Novo, unindo nacionalismo e autoritarismo. Assim, para ele, a "marcha para o Oeste" tinha como destino salvaguardar a "alma brasileira", fixando a "unidade espiritual" como garantia da "unidade política", num movimento de legítima defesa do Estado Nacional.

Entretanto, em oposição a este cenário, Oliveira (1998) se remete a Janaína Amado (1995), para falar sobre a diferença da conquista do Oeste no caso norte-americano e brasileiro.

Nos Estados Unidos, nos diz a autora, a história uniu-se ao mito para construir a identidade nacional; "a mito-história do Oeste fez parte da construção de uma hegemonia nacional e internacional" através de uma narrativa única capaz de simbolizar a nação. No Brasil, diferentemente, há dois espaços simbólicos da conquista do Oeste: o sertão e a Amazônia. São ambos mitos de caráter regional e não foram capazes de incluir a nação inteira em uma única narrativa (AMADO, 1995, p.67 apud LIPPI, 1998, p. 203).

As políticas de avanço e de desbravamento da fronteira interior, do oeste brasileiro, somaram-se a um esforço de construir um sentido único de nação. Assim, desenvolveu-se no Brasil um repertório de interpretações na literatura e nos relatórios de viajantes e militares cuja tônica voltava-se para o "Brasil Central" e/ou para aquilo que se convencionou chamar de "sertão".

Oliveira (1998) indica que, a depender da situação, o sertão, como lugar geográfico ou social, pode receber qualificações positivas ou negativas quanto a sua natureza ou a sua população. Em termos negativos, o sertão está associado com a aridez, como oposto ao litoral, como lugar distante dos povoamentos, das terras cultivadas e onde há predominância de tradições e costumes antigos, ultrapassados. Porém, apesar de se configurar como lugar inóspito e de adversidades, também pode apresentar o seu povo como "forte", capaz de vencer as barreiras da natureza. Em nossa interpretação, trata-se de uma visão bastante colonial do que é ser um "sertanejo forte", como se o sofrimento fosse algo natural e inerente à vida do povo sertanejo. Ela destaca que a diferença que há na caracterização do sertão e do sertanejo na literatura divide-se entre a perspectiva romântica - que exalta o admirável modo de vida sertanejo, visto como herói nacional e o sertão como ambiente idealizado - e a perspectiva realista - que aborda o sertão como problema para a nação e o sertanejo como um tipo miscigenado degenerado.

Outra contribuição para a discussão do sertão como fronteira interior, como sinônimo de natureza exuberante e ainda intocada, como linha divisória entre o civilizado e o incivilizado, entre humanos e sub-humanos, é recuperada a partir de Antonio Carlos Robert de Moraes (2011). O autor faz uma contribuição crítica à literatura e aos relatos modernistas que utilizaram o conceito de sertão para justificar a conquista produtiva do solo e de suas (não) gentes. Segundo ele, o sertão é o lugar do "outro", em oposição aos lugares domesticados, e foi uma imagem bastante disseminada para qualificar aquelas regiões que ainda não haviam sido incorporadas ao território brasileiro numa dinâmica mercantil nacional. Trata-se, então, de territórios para a expansão vindoura, com características bastante naturais e população composta por "selvagens". Os selvagens eram os "não incorporados", isolados, improdutivos, marginais que deveriam ser conquistados para que se desenvolvessem enfim.

Priscila Faulhaber (2001) aponta que as pesquisas desenvolvidas sobre a temática da fronteira pela Antropologia tinham como foco a observação da lógica do contato, de quão integrados ou assimilados estavam certos grupos indígenas à suposta "civilização" e/ou à sociedade economicamente mais desenvolvida. As pesquisas tinham, por sua vez, o objetivo de analisar o quanto as faixas de 
expansão da sociedade nacional incidiam sobre territórios habitados por populações tribais. Neste sentido, dentro do campo antropológico se destaca a ideia de "fronteiras étnicas" e de "fronteiras simbólicas" (identitárias e culturais), que provinham do contato de culturas distintas.

Por este viés, ocorre a reivindicação de direitos territoriais de alguns grupos justamente por suas diferenças culturais, estabelecendo limites entre estas diferentes etnias e a sociedade nacional. São sujeitos à margem, excluídos do sistema de relações sociais, e que reivindicam uma territorialidade própria. A partir da relação entre alteridades, "constroem sua 'auto-imagem' por meio da negação, da aceitação ou da exclusão do outro" (FAULHABER, 2001, p. 118). A autora insere tal discussão naquilo que denomina "Antropologia em fronteiras", na qual se desenvolvem concepções a respeito do movimento dialético entre identidades étnicas e nacionais, ou seja, da dinâmica de expansão das frentes da sociedade nacional e das fronteiras identitárias internas.

Ainda na Antropologia, destacam-se também os estudos realizados por pesquisadores da chamada "Turma do Brasil Central", vinculados a projetos de pesquisa do Museu Nacional. Dentre eles, destacamos as contribuições de Otávio Velho sobre a temática da fronteira, o qual teve como área de estudo a Amazônia Oriental. Suas análises se fundam especialmente no sudeste do Pará - Bico do Papagaio - região de Marabá, que fora atravessada em 1972 pela rodovia Transamazônica. Trata-se, segundo Velho, de uma área que é ponto de contato entre a Amazônia, o Nordeste e o Brasil Central, constituindo, por esta razão, interesse para sua investigação.

Guedes (2013) indica que Otávio Velho, em sua dissertação, buscou descrever historicamente o avanço de várias frentes econômicas: a frente pastoril, as frentes extrativistas da borracha, da castanha, do diamante e da mineração, de uma maneira geral, assim como novas frentes agrícolas e pecuárias. Já em sua tese, onde Velho se aprofunda no debate das relações entre estado, capitalismo autoritário e campesinato, "o importante não é o estudo da fronteira por ela mesma, mas sim, como ocorreu o desenvolvimento capitalista a partir da fronteira" (VELHO, 1979, p. 14 apud SANTOS, 2013, p.121). Segundo Faulhaber (2001), em suas pesquisas, Otávio Velho recorre às teorias de Frederick Turner (1996) e ao caso norte-americano para refletir sobre as condições de existência de uma fronteira livre na Amazônia e, a partir daí, propor a construção de um modelo de análise generalizável sobre a fronteira.

Em todas estas abordagens pode-se depreender que a fronteira foi e ainda é utilizada como categoria de análise não só para os sentidos da construção da nação e de integridade territorial, como também está associada com a diferenciação do "outro", sendo um marcador de separação entre os integrados e os não integrados a esta mesma nação, mas também do grau de desenvolvimento do capitalismo em determinadas porções do território nacional.

\section{ALCANÇAR O ELDORADO E DOMESTICAR O SELVAGEM: A INTEGRAÇÃO ESTATAL DA AMAZÔNIA}

Vimos que a construção dos espaços simbólicos do imaginário nacional brasileiro perpassa tanto a ideia de conquista do que se denomina por "sertão" quanto de "oeste". A fronteira brasileira, por excelência, eldorado para onde se invocam esses imaginários, só poderia ser a Amazônia, região esta que ainda não fora plenamente ocupada e cujo senso comum enxerga como uma grande floresta depopulada e, por isso, espaço ideal para a integração. Segundo Porto-Gonçalves (2008), as imagens criadas a respeito desta região são sempre sobre a Amazônia, nunca da própria Amazônia, que é vista meramente como um reservatório de recursos ou como um vazio demográfico. Neste sentido, torna-se necessário carregar um projeto civilizatório para ocupar e transformar sua natureza ainda, em grande parte, "selvagem".

Ruy Moreira (2012) auxilia na compreensão das diferenças da colonização das fronteiras brasileiras a partir dos "vetores fundacionais" que foram instituídos pelo processo colonial no Brasil: o bandeirantismo, no século XVI, regido pelos bandeirantes; a catequese jesuítica, a partir do século $\mathrm{XVI}$, regida pela Igreja Católica; e a expansão do gado ou o tropeirismo praticada a partir do século XVII no Brasil pelos tropeiros, personagens históricos que agiam de modo menos espontâneo e mais fiel às demandas de exploração da metrópole.

$\mathrm{Na}$ Amazônia, assim como em outros espaços interiores do Brasil, a ocupação da fronteira na época colonial se deu por avanços em forma de "impulsos", sempre dados pela restrição do uso da terra e pela perspectiva de obter "riquezas fartas e imediatas por meio da extração e produção de bens primários" (SILVA et al., 2014, p. 45) Assim, foram atingidas áreas normalmente distantes entre si, que não configuraram uma ocupação sistemática e ordenada do território, muito menos planejada, criando bolhas de ocupação que foram por vezes abandonadas e esquecidas pelos colonos e pelos governos centrais após a exploração de recursos até a exaustão - as chamadas "fronteiras ocas" (hollow frontiers) (SILVA et al., 2014).

No século XIX observa-se uma ação mais orientada em termos estatais para a ocupação da região. De acordo com Arbex Jr. (2005), impulsionadas pela valorização da borracha no mercado mundial

$\begin{array}{lllll}\text { Caminhos de Geografia } & \text { Uberlândia-MG } & \text { v. 23, n. } 85 & \text { fev./2022 } & \text { p. 315-329 Página } 319\end{array}$


após a descoberta da técnica de vulcanização, as incursões mais efetivas na Amazônia derivam da extração do látex, que prosperou até o início do século $X X$, coincidindo com o auge da economia do café no sudeste. Tal economia atraiu uma série de migrantes, especialmente do nordeste, de tal modo que entre os anos de 1872 e 1920, a população da região cresceu 4,3 vezes, passando de 332.847 para 1.439.052 habitantes. Após o declínio do ciclo, muitos retornaram para seus lugares de origem e, entre 1920 e 1940, a população amazônica teve um incremento menos significante.

É só durante os governos de Getúlio Vargas que a região passou a ser prioridade nos planos de desenvolvimento e de integração nacionais. Vargas sinalizou para investimentos no setor industrial brasileiro, tendo como grandes realizações a criação das empresas Companhia Siderúrgica Nacional - CSN (1941), Vale do Rio Doce (1942) e Petrobrás (1953). Acompanhado da proposta de um desenvolvimento interno e soberano, o varguismo ${ }^{1}$ apontou também para uma política de ocupação e exploração dos recursos no Centro-Oeste e Amazônia. Foram criadas, na época, colônias de povoamento, como em Dourados (MS), Ceres (GO), bem como foi realizada a primeira expedição oficial na região do Araguaia, a Roncador-Xingu, realizada pelos irmãos Villas-Boas. Por meio do Serviço de Proteção ao Indio (SPI), a expedição estabeleceu os primeiros contatos com indígenas, contribuindo especialmente para a implantação do Parque Nacional do Xingu (ARBEX JR, 2005; OLIVEIRA, 2005).

Além disso, também é da Era Vargas a criação de instituições federais encarregadas de formular planos para ocupar e integrar o território nacional, como o Conselho Nacional de Geografia, o Conselho Nacional de Cartografia e o Conselho Nacional de Estatística, reunidos ao Instituto Brasileiro de Geografia e Estatística (IBGE) a partir de 1938; ou mesmo a criação da Fundação Brasil Central (FBC), em 1943. A FBC teve como tarefa organizar o processo de ocupação do interior isolado do país.

Segundo Coy; Klinger; Kohlepp (2017), durante o Estado Novo, novas dinâmicas de deslocamento se dão a partir da Marcha para o Oeste, quando a ação bandeirante do séc. XVII é resgatada, com o intuito de promover uma exploração e ocupação efetivas no interior do país. Assim, foi se fortalecendo o mito do frontier, especialmente a partir da materialização da expansão através da construção de infraestruturas e da criação de colônias de povoamento agrícola, como continuidade da colonização agrícola já existente na região sul do Brasil. O Centro-Oeste e a Amazônia passaram a ser as regiões de maior atração de grupos de sulistas e sudestinos interessados em conquistar definitivamente um pedaço de terra para produzir.

De acordo com Ariovaldo Umbelino de Oliveira (2005), o Estado caminhou em conjunto com o capital privado na execução de investimentos na região. Dos projetos de colonização privados provinha o lucro sobre a venda das terras para camponeses e colonos. Ao Estado coube a contenção das tensões sociais, fazendo com que os próprios projetos de colonização funcionassem como uma "válvula de escape" para áreas de tensão social em outras partes do país, evitando assim encarar a reforma agrária. Assim, a Marcha se constitui num movimento duplo de colonização e expansão do agronegócio na fronteira.

Nas décadas de 1950 e 1960, durante o governo de Juscelino Kubitschek - JK (1956-1960) e, posteriormente, com a Ditadura Militar (1964-1984), foi dado novo impulso para a integração e desenvolvimento do Centro-Oeste e da Amazônia: a construção de Brasília passaria a servir como marco geoestratégico para a integração com as "periferias" nacionais, rompendo com o isolamento daquelas regiões. Porto-Gonçalves (2008) reforça o caráter supostamente nacionalista nas propagandas, apesar de práticas entreguistas sobre a região, contradição reforçada pelo slogan "integrar para não entregar", disseminado durante o Regime Militar. É no período militar que a propaganda da Amazônia como um grande vazio demográfico é ressaltada, de modo a justificar a sua ocupação, inclusive por estrangeiros. Outro slogan do período, "terra sem homens para homens sem terra", estimula a migração de sem-terra para a região, incentivando os processos de colonização.

A saída para a ocupação foi produzir uma integração física por rodovias e ferrovias, mas também criar as condições necessárias para a produção e a atração de investimentos como, por exemplo, através da realização de grandes obras de infraestrutura, como hidrelétricas para a geração de energia ou o estabelecimento de projetos minerais. Portanto, iniciadas por JK e continuadas pelos militares, são criadas as principais rodovias de interligação norte-sul e leste-oeste da Amazônia, como é o caso da Belém-Brasília (BR-010), construída entre 1950 e 1974, da Brasília-Cuiabá-Porto Velho (BR-364), iniciada em 1960, da Cuiabá-Santarém (BR-163), iniciada em 1971, da BR-158, que liga o

\footnotetext{
1 Para o historiador Alessandro Batistella (2018), a ascensão do presidente Getúlio Vargas ao poder em 1930 foi uma mudança paradigmática em relação ao "liberalismo excludente" da Primeira República, pois se implantou no Brasil um Estado centralizado e intervencionista que ambicionava modernizar e industrializar o Brasil por meio de um projeto nacional-desenvolvimentista. Neste sentido, observam-se dois fenômenos: o getulismo e o trabalhismo. Enquanto o primeiro refere-se a um fenômeno sentimental, uma espécie de culto a Getúlio Vargas,
} o segundo é um movimento político-partidário e/ou ideológico (SANTOS, 2018).

$\begin{array}{lllll}\text { Caminhos de Geografia } & \text { Uberlândia-MG } & \text { v. 23, n. } 85 & \text { fev./2022 } & \text { p. 315-329 Página } 320\end{array}$ 
Pará ao Rio Grande do Sul, ou da Rodovia Transamazônica (BR-230), cujas obras se iniciaram em 1972.

As novas rodovias foram atrativas para uma sorte de pessoas, que passaram a buscar terras a preços menores, devido à distância para os grandes centros dinâmicos, o que compensava 0 investimento. Assim, vieram "colonos, latifundiários, investidores, mas também caçadores de sorte e aventureiros" (COY; KLINGER; KOHLEPP, 2017, p.18 e 19). Para Porto-Gonçalves (2008), a organização do espaço amazônico, que se dá tradicionalmente e em consonância com a ecologia regional através do padrão "rio-várzea-floresta", é crescentemente substituído pelo padrão "estradaterra firme-subsolo", modificando as estruturas regionais sem, no entanto, atender às especificidades ecológicas e sociais.

Entretanto, não foi só a terra, mas o subsolo que, na década de 70 , passou a ser alvo da cobiça na Amazônia. O garimpo, desde então, também aparece como uma questão central na região, seja ele do tipo empresarial ou cooperativo (PORTO-GONÇALVES, 2008). Do garimpo também resultaram conflitos e contradições, de modo que os colonizadores, latifundiários e políticos tradicionais transformaram-se em proprietários dos mesmos, dominando o controle da atividade, que era executada inicialmente pelos colonos e posseiros (OLIVEIRA, 2005).

Após as pesquisas realizadas pelo Projeto Radam-Brasil, investimento do governo na pesquisa de recursos naturais, foram reveladas províncias minerais, como Carajás, no sudeste do Pará. Também se estabeleceu nas proximidades de Oriximiná um complexo mínero-metalúrgico para a exploração de ferro, cobre, ouro, bauxita e outros minérios (PORTO-GONÇALVES, 2008). As pesquisas passaram a ocorrer em parceria com órgãos e empresas do governo junto a empresas estrangeiras, e - Estado passou a fazer concessões a grupos nacionais e internacionais interessados em trazer o "desenvolvimento" para a região.

Este modelo de ocupação baseado nas colonizações agrárias, minerárias e na construção de infraestruturas determinou algumas supostas "vocações" econômicas para a Amazônia, que sempre tratada como vazio demográfico e área de reserva natural, canalizou novos fluxos de matéria e energia, provenientes de investimentos de capitais do centro sul do país e também internacionais. No entanto, hoje, há processos escalares mais complexos voltados para a região.

As dinâmicas dos frontiers são então mais fortemente modificadas por variáveis político-institucionais, econômicas e culturais cujos processos de negociações são cada vez mais decididos a níveis de escalas superiores, desatrelando contextos de esclarecimentos locais e nacionais (LAMBIN; GEIST, 2006). Isto se torna visível pelo significado dos mecanismos de mercado orientados pela exportação, cujas determinantes diretas mais importantes para a região de estudos hoje são a expansão da monocultura mecanizada da soja, a pecuária extensiva, projetos de infraestrutura da produção de energia (vide hidrelétrica Belo Monte) e a extração mineral. (...) Com isso, os frontiers da Amazônia do séc. XXI estão marcados como frontiers de recursos e mais do que nunca pela mudança dos mecanismos de mercado e pela pressão pela incorporação global e uso de recursos subterrestres, da floresta e da terra (COY; KLINGER; KOHLEPP, 2017, p.29 e 30).

Décadas depois, a tendência à ocupação estrangeira com o auxílio do estado permanece através de uma neocolonização, que se dá a partir de grandes projetos de desenvolvimento ou por estratégias mercantis e financeiras, inclusive pelo exemplo da estrangeirização de terras no país, onde terras ainda pouco exploradas têm sido alvo de negócios financeiros, sendo vultuosamente apropriadas por grupos internacionais, tal como sugerido pela prática do "land grabbing" (SAUER, 2010).

Em consonância à visão paradoxal que evidencia tanto o imaginário da Amazônia como subdesenvolvida e arcaica, quanto como eldorado ou lócus da natureza sacralizada, resta apenas uma alternativa: a de ocupá-la para mercantilizar e privatizar os recursos que oferece. As pressões externas geradas nos biomas da Amazônia e do Cerrado são incomensuráveis, resultando na desintegração do subsolo, do solo e da floresta, mas também, inevitavelmente, nas pressões sobre os "obstáculos" ao "desenvolvimento", que são os próprios povos que habitam a região, como indígenas, ribeirinhos, quilombolas, pequenos agricultores e comunidades tradicionais de toda sorte, em suma, os povos da floresta e os povos do cerrado.

Segundo Brum (2020), as áreas e os financiamentos públicos oferecidos pelo estado brasileiro sempre alimentaram um mercado de especulação em torno das terras na região amazônica. Ocorre que hoje, mais do que nunca, o Estado também tem atuado na regularização da grilagem em terras públicas, transformando grileiros em latifundiários bem sucedidos, que se utilizam deliberadamente de práticas criminosas, como a pistolagem e os incêndios intencionais, para "limpar o terreno" de floresta e de gente, dois elementos considerados entraves ao que se considera ser o desenvolvimento e à modernização. Isso expressa o colonialismo interno² recorrente no processo de ocupação do espaço

2 A categoria de "colonialismo interno", amplamente debatida por Casanova (2006) e por outros autores e autoras aqui mencionados, leva em conta que apesar do fim do período colonial enquanto recorte temporal específico da história econômica de regiões do planeta, as estruturas coloniais se prolongaram, caracterizando relações de
Caminhos de Geografia
Uberlândia-MG
v. 23, n. 85
fev./2022
p. 315-329
Página 321 
agrário no Brasil e, sintetiza, a partir dos números da violência no campo, como as políticas do estado têm historicamente contribuído para a situação de barbaridade em que se encontram os povos na Amazônia hoje.

\section{EXPROPRIAÇÃO E VIOLÊNCIA NA FRONTEIRA AMAZÔNICA}

Ao que tudo indica a exploração predatória da Amazônia e o oferecimento dos seus recursos para o resto do mundo sempre foi uma política de Estado. Pendendo ora para um discurso nacionalista, ora para a execução de novos projetos minerários, agrícolas, madeireiros e outros por corporações internacionais, o Estado se torna o principal agente e cúmplice do cenário na Amazônia hoje, inclusive pela permissibilidade para com negócios ilegais, tais como a própria exploração de madeira, de ouro nos garimpos, o tráfico de drogas ou a biopirataria.

Esta condição é profundamente enraizada nas políticas de Estado, mas também na própria sociedade, que lida com a Amazônia como a eterna fronteira a ser ocupada. Grupos políticos e econômicos locais, regionais e nacionais corroboram com este tratamento, contribuindo para que a região se posicione de forma periférica, marginal, dependente e colonial em termos de sua economia. Ela ocupa, portanto, dentro da Divisão Nacional e Internacional do Trabalho, um lugar de exportadora de matérias-primas (celulose, ferro, cobre, bauxita...), alternando-se entre atividades extensivas ou extrativistas. Por isso, sobre a Amazônia desenha-se uma geografia econômica da exclusão: sua incorporação não se dá em respeito às condições culturais e ecológicas, mas pelos valores definidos pelos “de fora" (PORTO-GONÇALVES, 2008).

Figura 1 - Amazônia Legal (2019): Limites administrativos da região, 2019.

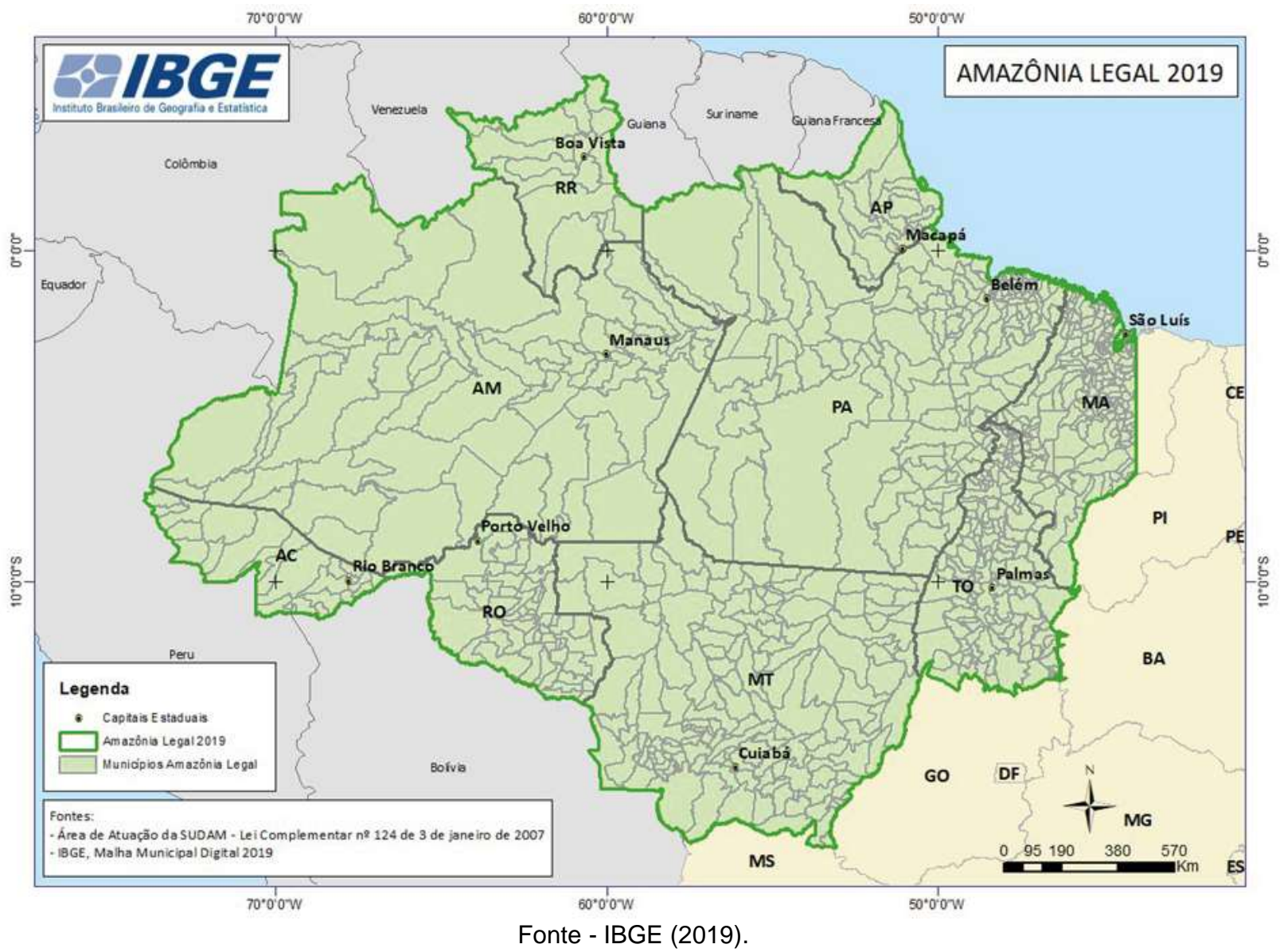

dominação e exploração heterogêneas dentro de sociedades anteriormente coloniais. O colonialismo interno é representado, então, pela dominação de alguns setores da sociedade sobre outros, como classes dominantes burguesas sobre povos indígenas, por exemplo, no Brasil e na América Latina como um todo, expressando uma estrutura social que reproduz, ainda hoje, a colonialidade do poder e do saber.
Caminhos de Geografia
Uberlândia-MG
v. 23, n. 85
fev./2022
p. $315-329$
Página 322 
De acordo com Moraes (2002; 2011), nas periferias do capitalismo, a dominação se objetiva sem a alocação de grandes massas de capital no espaço, o que resulta num padrão espoliativo do ponto de vista geográfico e de empobrecimento local. A baixa alocação de recursos, no entanto, não implica em baixos níveis de exploração da natureza, dado que, pelo contrário, ocorre uma verdadeira "drenagem" da riqueza localizada nos fundos do território. Segundo Moraes (2011), as áreas periféricas foram, desde sempre, fornecedoras de produtos naturais, tendo como base o extrativismo vegetal, a exploração mineral, a agricultura ou a pecuária. São, em suas palavras, "fundos territoriais" para o capital, reservas de valor de mercado em vias de incorporação, mas ainda não plenamente incorporadas.

Periodicamente, ocorrem ondas sucessivas de "modernização" nas periferias do capitalismo, como forma de ajustes constantes oriundos das demandas dos países centrais que, de modo cíclico, readequam as sub-economias às relações dominantes e incorporam determinadas áreas geográficas ao cerco econômico. Assim sendo, "nos espaços periféricos, as formas de valorização do espaço introduzidas pela subordinação dos lugares à lógica e à dinâmica do capitalismo não reproduzem especificamente o 'modelo' de valorização capitalista do espaço" (MORAES, 2002, p. 20). A fronteira, em grande parte das vezes encarada como "ponta de lança" e "veículo de colonização" das últimas periferias de interesse do capitalismo (COY; KLINGER; KOHLEPP, 2017).

No decorrer das suas pesquisas sobre o tema da fronteira, José de Souza Martins, que teve grande parte dos seus campos realizados na Amazônia, afirmou que o que se coloca em choque na fronteira não é apenas a disputa por um recurso natural, mas precisamente um embate entre "mundos" incompatíveis e diferentes. A fronteira, diz ele, "é essencialmente o lugar da alteridade" (MARTINS, 1997, p.150), de uma alteridade não só econômica, mas moral. Assim, essencialmente, a fronteira tem como elemento fundante o conflito, conflito que se dá na incompatibilidade entre diversos mundos e perspectivas.

(...) a fronteira de modo algum se reduz e se resume à fronteira geográfica. Ela é fronteira de muitas e diferentes coisas: fronteira da civilização (demarcada pela barbárie que nela se oculta), fronteira espacial, fronteira de culturas e visões de mundo, fronteira de etnias, fronteira da História e da historicidade do homem. E, sobretudo, fronteira do humano. Nesse sentido, a fronteira tem um caráter litúrgico e sacrificial, porque nela o outro é degradado para, desse modo, viabilizar a existência de quem o domina, subjuga e explora (...). É na fronteira que encontramos o humano no seu limite histórico (MARTINS, 1997, p.13).

A Amazônia é encarada como uma dessas áreas periféricas, como área de fronteira em vias de valorização e, portanto, onde o humano encontra-se no seu limite histórico. A fronteira amazônica exprime-se, na realidade, como uma zona síntese do conflito e, por isso, lócus da manifestação e combinação das formas da violência. Neste sentido, a ideia de modernização traz em si a brutalidade, o genocídio e a devastação como elementos constituintes.

Este fato acarreta numa particularidade de acumulação originária nas periferias e impõe um desenvolvimento geográfico desigual e violento. Eliane Brum (2019), no entanto, aponta para uma inadequação do uso do termo "periferia", pois embora habitualmente a Amazônia seja referida como uma periferia, tudo aponta para o seu oposto: não se trata mais de dizer que a região está na periferia do mundo, visto que se encontra no centro das disputas políticas, econômicas e ambientais da atualidade, ou seja, está no centro do mundo.

Para exemplificar, só nos quatro primeiros meses de 2019, a Comissão Pastoral da Terra (CPT) registrou dez assassinatos em conflitos no campo no Brasil. Cinco destes foram de Nazildo, Dilma, Claudionor, Hilton e Carlos. No segundo semestre, no mês de outubro de 2019, um dos assassinatos que se tem registro é o de Alexandre. Adiante, estas vítimas serão brevemente contextualizadas a partir de suas inserções territoriais.

Nazildo dos Santos Brito ${ }^{3}$ era uma liderança quilombola. Residia na comunidade Turê III, no nordeste do Pará, entre Tomé-Açu e Acará, e vinha sofrendo ameaças por denunciar crimes ambientais na região. O fazendeiro José Telmo Zani, assassino do quilombola, fazia extração ilegal de madeira dentro do território quilombola ao qual Nazildo pertencia.

${ }^{3}$ Informações retiradas do portal Amazônia Real. Disponível em: https://bit.ly/3ojKM9Z.

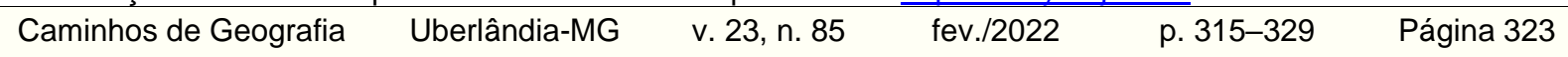


No município de Baião, nordeste do Pará, Dilma Ferreira da Silva ${ }^{4}$, que era militante do Movimento dos Atingidos por Barragens (MAB), foi degolada por arma branca, com suspeitas de estupros e torturas. Ela foi morta junto com seu marido, Claudionor Costa da Silva, e seu amigo assentado, Hilton Lopes. Todos os três residiam no Assentamento Salvador Allende, criado pelo Instituto Nacional de Colonização e Reforma Agrária (Incra) na área da antiga fazenda Piratininga, ocupada por mais de quatrocentas famílias sem-terra há mais de dez anos. Desde o início, o local sofreu com ataques de pistoleiros e conflitos com madeireiros, além de ameaças constantes.

Carlos Cabral Pereira 5 foi abordado por dois homens em uma moto, que dispararam contra ele três tiros, sendo dois na cabeça. Como ambos usavam capacete, foi dificultado o reconhecimento de suas identidades. Carlos era o presidente do Sindicato dos Trabalhadores e Trabalhadoras Rurais (STTR) de Rio Maria, sudeste do Pará.

Alexandre Coelho Furtado Neto ${ }^{6}$ retornava para sua barraca no acampamento 1.200, em Ourilândia de Norte, no sudeste paraense, quando foi surpreendido por uma emboscada e atingido com um tiro de espingarda no peito. Ele era uma liderança da ocupação e lutava pelo assentamento dos agricultores desde 2006. Dos 1.200 alqueires totais da fazenda, 470 são de área pública, sendo esta a parcela ocupada por setenta famílias sem-terra, inclusive a de Alexandre. Na justiça, o fazendeiro Eutimio Lippaus afirmou ser o dono da fazenda e solicitou a reintegração de posse. Ao longo do ano houve tiroteios, ameaças e incêndios criminosos contra as famílias acampadas. Porém, sem o amparo necessário, Alexandre foi mais uma vítima fatal.

De um lado estão os fazendeiros José Telmo Zani e Eutimio Lippaus, o desmatamento e a exploração de madeira ilegal ou as ameaças por parte de pistoleiros. Do outro estão denúncias da exploração ilegal de madeira, pequenos/as agricultores/as, assentados/as da reforma agrária, quilombolas, atingidos/as por barragens, acampados/as, pessoas que lutam pela conquista de um pedaço de chão. Não à toa, observa-se que todos os incidentes ocorreram na Amazônia Legal, considerada uma das últimas grandes fronteiras do país. O aumento de conflitos por terra já vem sendo observado desde 2016, ano de golpe de estado, quando Michel Temer assumiu a presidência da república, tendência essa que vem tendo continuidade com o governo Bolsonaro, conforme indica a tabela 1.

Tabela 1 - Comparação dos conflitos no campo no Brasil (2009-2018).

\begin{tabular}{|l|c|c|c|c|c|c|c|c|c|c|c|}
\hline & $\mathbf{2 0 0 9}$ & $\mathbf{2 0 1 0}$ & $\mathbf{2 0 1 1}$ & $\mathbf{2 0 1 2}$ & $\mathbf{2 0 1 3}$ & $\mathbf{2 0 1 4}$ & $\mathbf{2 0 1 5}$ & $\mathbf{2 0 1 6}$ & $\mathbf{2 0 1 7}$ & $\mathbf{2 0 1 8}$ \\
\hline \multicolumn{8}{|c|}{ CONFLITOS POR TERRA } \\
\hline Ocorrências & 528 & 638 & 805 & 816 & 763 & 793 & 771 & 1.079 & 989 & 964 \\
\hline Ocupações & 290 & 180 & 200 & 238 & 230 & 205 & 200 & 194 & 169 & 143 \\
\hline Acampamentos & 36 & 35 & 30 & 13 & 14 & 20 & 27 & 22 & 10 & 17 \\
\hline Total & $\mathbf{8 5 4}$ & $\mathbf{8 5 3}$ & $\mathbf{1 . 0 3 5}$ & $\mathbf{1 . 0 6 7}$ & $\mathbf{1 . 0 0 7}$ & $\mathbf{1 . 0 1 8}$ & $\mathbf{9 9 8}$ & $\mathbf{1 . 2 9 5}$ & $\mathbf{1 . 1 6 8}$ & $\mathbf{1 . 1 2 4}$ \\
\hline Assassinatos & 25 & 30 & 29 & 34 & 29 & 36 & 47 & 58 & 70 & 25 \\
\hline
\end{tabular}

Se em 2015 foram 771 ocorrências de conflitos por terra no Brasil, em 2016 esse número saltou para 1079. Em 2017, foram 989 ocorrências e em 2018, 964. Como reflexo, observa-se a diminuição das ocupações de terras e formações de acampamentos e retomadas, ou seja, a diminuição das práticas de resistência no campo. Além disso, se em 2015 o número de assassinatos no campo vitimou 47 pessoas, em 2016 esse número subiu para 58 vítimas e, em 2017, foram 70 pessoas, representando um salto gritante das vítimas fatais. Em 2018, foram registradas 25 vítimas. A redução de ocorrências de conflitos e assassinatos em 2018, no entanto, não demonstra uma tendência confiável de diminuição, mas está associada ao fato deste ter sido um ano eleitoral, quando costuma haver uma sensível atenuação dos casos.

${ }^{4}$ SARRAF, Moisés. Coordenadora do MAB é morta com requinte de crueldade no Pará. Amazônia Real, 22 de março de 2019. Disponível em: https://bit.ly/3eRbjrZ.

5 GLOBO.COM. Ameaçado de morte, sindicalista rural é assassinado a tiros no interior do Pará. 11 de junho de 2019. Disponível em: http://glo.bo/3cbtyXQ.

${ }^{6}$ CPT ALTO XINGU. Nota de Repúdio pelo assassinato do companheiro Alexandre [online]. Tucumã, 21 de outubro de 2019.

$\begin{array}{lllll}\text { Caminhos de Geografia } & \text { Uberlândia-MG } & \text { v. 23, n. } 85 & \text { fev./2022 } & \text { p. 315-329 Página } 324\end{array}$


Segundo a CPT (2019), o discurso bélico do atual presidente e de seu governo tem contribuído para acirrar o clima de tensão na região da Amazônia Legal, além, notadamente, dos efeitos da suspensão de políticas de reforma agrária, da paralisação nas desapropriações de terra para assentamentos, do bloqueio da demarcação de terras indígenas e outros mecanismos e políticas que representam retrocessos e perda de direitos para os povos do campo. Por outro lado, há claro incentivo para que latifundiários, garimpeiros, madeireiros e outros grupos hegemônicos retomem e utilizem áreas protegidas (como unidades de conservação ou terras indígenas) para exploração mineral, bem como há estímulo explícito para o armamento em "legítima defesa" por parte destes agentes do campo. A tônica é combater e expulsar famílias sem terra, indígenas e comunidades tradicionais consideradas "inimigas da nação e do progresso", cidadãos "do mal", que são tratados como empecilhos em áreas de interesse do capital na fronteira.

Dados recentes do Instituto Nacional de Pesquisas Espaciais (INPE) demonstram o aumento de focos de queimadas na Amazônia Legal, o aumento do desmatamento e da atuação de garimpos ilegais em estados como Pará e Roraima, informações estas contestadas pelo presidente da república. Indígenas e ambientalistas atribuem o avanço e as ofensivas na região às declarações do mesmo em favor da exploração mineral em terras indígenas e ao afrouxamento no combate a crimes ambientais pelo atual governo (BBC NEWS BRASIL, 2019).

A violência, entendida aqui a partir de múltiplas estratégias - sendo a mais extrema delas o assassinato - é parte da dinâmica monopolizadora de territórios para grupos hegemônicos capitalistas nacionais e internacionais em detrimento das populações locais, que possuem outros hábitos e relações costumeiras de ocupação de tais territórios. Levantamento recente realizado pelo portal "De olho nos ruralistas" originou um mapa que demonstra que na Amazônia Legal e na região do projeto de ocupação do agronegócio, o MATOPIBA (que abarca estados do Maranhão, Tocantins, Pirauí e Bahia), estão concentradas as maiores áreas de terras pertencentes a congressistas brasileiros. Este fato demonstra que há relações umbilicais e até mesmo corresponsabilidade dos parlamentares brasileiros com o aumento da violência do campo, seja direta ou indiretamente, através da dispersão de discursos, ou através da dispersão de projetos de incorporação dos chamados "fundos territoriais" ainda disponíveis (MORAES, 2011).

Tabela 2 - Ranking dos cinco estados com maiores registros de conflitos no campo em 2018.

\begin{tabular}{|l|l|l|l|l|}
\hline Estado & $\begin{array}{c}\text { Amazônia } \\
\text { Legal ou } \\
\text { MATOPIBA? }\end{array}$ & $\begin{array}{c}\text { № de } \\
\text { conflitos }\end{array}$ & $\begin{array}{c}\text { Pessoas } \\
\text { envolvidas }\end{array}$ & Posição \\
\hline Maranhão* & $\operatorname{Sim}$ & 201 & 80.803 & $1^{\circ}$ \\
\hline Bahia & $\operatorname{Sim}$ & 182 & 156.027 & $2^{\circ}$ \\
\hline Pará & $\operatorname{Sim}$ & 177 & 311.377 & $3^{\circ}$ \\
\hline $\begin{array}{l}\text { Minas } \\
\text { Gerais }\end{array}$ & Não & 146 & 36.227 & $4^{\circ}$ \\
\hline Rondônia & $\operatorname{Sim}$ & 77 & 58.700 & $5^{\circ}$ \\
\hline
\end{tabular}

Maior $\mathrm{n}^{\circ}$ de ameaças de morte em $2018=56$

** Maior $n$ ㅇ de assassinatos em $2018=16$

Fonte - Elaboração própria (2019) com base em dados da Comissão Pastoral da Terra (2019).

Outro aspecto decorrente dos casos mencionados anteriormente é o fato de Nazildo, Dilma, Claudionor, Hilton, Carlos e Alexandre terem sido assassinados no estado do Pará. Também segundo o caderno de conflitos no campo da CPT (2019), o Pará é o estado onde vivem $51 \%$ de todas as pessoas vítimas de conflitos no campo em 2018, sendo recordista em número de assassinatos no campo. Nos últimos 40 anos ocorreram 53 execuções de lideranças camponesas no estado, dentre eles religiosos, sindicalistas, advogados ou ambientalistas, fora que dentre os 49 massacres registrados no país, 28 deles se deram lá (BRASIL DE FATO, 2019). Mas a tendência de ocupação de novas fronteiras e de acentuação de conflitos do Pará, também se observa em outros estados da Amazônia Legal, como Maranhão, Mato Grosso e Rondônia (tabela 2). Além disso, o estado da Bahia tem se revelado um palco de conflitos, especialmente de conflitos em torno da água, como os

$\begin{array}{llllll}\text { Caminhos de Geografia } & \text { Uberlândia-MG } & \text { v. 23, n. } 85 & \text { fev./2022 } & \text { p. 315-329 } & \text { Página } 325\end{array}$


ocorridos em Correntina. Os conflitos estão associados à expansão do agronegócio em decorrência do projeto MATOPIBA, razão pela qual o estado do Maranhão, que pertence parcialmente a Amazônia e que possui limites inseridos no MATOPIBA, também esteja apresentando cada vez mais casos de violência no campo.

Para De Angelis (2012), o processo de acumulação primitiva, para além de ter significado o momento histórico de apartamento do produtor dos seus meios de produção - transformando-o em um trabalhador assalariado que tem por finalidade a produção da mais-valia para o patrão - possui um caráter contínuo ao longo do tempo e espaço. O capital detém uma capacidade ilimitada de se expandir, promovendo uma acumulação permanente, que se choca contra limites dados por áreas geográficas "às margens", ainda não afetadas totalmente pela produção capitalista.

Consequentemente, o que se vê como processo contínuo é o que Michael Levien (2014) define como "regimes de desapropriação". Apesar de conceder o mérito a David Harvey (2004) em sua teoria sobre a "acumulação por espoliação" - que, segundo Levien, libertou a acumulação primitiva do vínculo com a instauração do modo de produção capitalista - a perspectiva dos "regimes de desapropriação" ultrapassa a retórica da acumulação primitiva para firmar-se como uma função permanente no capitalismo. Em diferentes contextos históricos e geográficos a desapropriação de terras rurais vem sendo utilizada como artifício de criação de novos espaços (e por que não fronteiras?) para a implantação de projetos de desenvolvimento, grande parte deles de usos não agrícolas. Tais regimes são viabilizados por meio de mecanismos de coerção extraeconômicos coordenados pelo próprio Estado, de modo a beneficiar a classe que ele representa. Desta maneira, afirma o autor, trata-se de um processo evidentemente político, avesso a uma possível leitura de que apenas se implica aí um suposto automatismo do capital (LEVIEN, 2014).

A região amazônica é hoje o principal alvo de um regime de desapropriação de terras, águas e territórios, visto que lá as florestas e os solos ainda não foram completamente incorporados na circulação do capital, constituindo-se ainda como "fundos territoriais" (MORAES, 2011). Por isso, a fronteira espacial é ali tão disputada, tornando-se uma chave analítica para a visualização daquilo de um processo de desenvolvimento geográfico desigual. A geografia histórica do capitalismo demonstra uma desigualdade na distribuição dos chamados "recursos naturais" - como terras agricultáveis ou reservas minerais, hídricas e da biodiversidade-, mas também dos "recursos humanos" - como a força de trabalho, os costumes locais e a cultura. "Tudo isto é geograficamente diferenciado e localizado e sua apropriação, portanto, depende de estratégias espaciais para ganhar acesso e comando sobre eles" (HARVEY, 2007, p.34 - tradução nossa). Estas estratégias se dão de maneiras tão variadas quanto violentas, tanto em termos de agentes quanto de formas, utilizando-se inclusive do roubo e da rapinagem dos bens ecológicos, mas também de vidas humanas. Em vista disso, o desenvolvimento geográfico desigual tem como força fundamental a acumulação e a geração de valorização e desvalorização por meio da expropriação.

\section{CONSIDERAÇÕES FINAIS: O FUTURO QUE NUNCA CHEGA}

O propósito deste artigo foi realizar um breve panorama da situação de conflito e da violência no campo, especialmente a partir de dados recentes, datados especialmente entre 2009 e 2019. Sem a pretensão de esgotar o debate, o principal objetivo era demonstrar duas evidências: a primeira delas, a de que as áreas de fronteira, vistas como fundos territoriais de recursos e de investimentos são áreas onde ocorre a maior parte dos conflitos no campo e, portanto, pode-se afirmar que há relações notáveis entre fronteira e violência; a segunda, a de que a Amazônia Legal, ao se constituir como área de expansão por excelência - o "oeste" e "sertão" a ser civilizado - é, também, inevitavelmente, a região onde se concentram os dados mais mórbidos no campo brasileiro.

Neste sentido, construída historicamente como "a periferia da periferia", por um duplo esforço recorrente entre colonialismo e planejamento de Estado - os quais estiveram ancorados em inversões de capital privado desde o princípio - a Amazônia é, na realidade, elemento central para a acumulação por espoliação e para o fortalecimento de regimes de desapropriação. Se por um lado é uma região com aporte abrupto de investimentos capitalistas, por outro lado, é onde se revelam as maiores brutalidades e apagamentos, seja dos indivíduos e grupos populacionais subestimados em suas humanidades, que secularmente ali habitam, seja pelo desprezo da sua própria natureza e do equilíbrio ecossistêmico, atualizado pelas atuais queimadas propositalmente descontroladas na região, estendidas também ao Pantanal. Ainda que o fogo dos incêndios criminosos emane brasas

$\begin{array}{lllll}\text { Caminhos de Geografia } & \text { Uberlândia-MG } & \text { v. 23, n. } 85 & \text { fev./2022 } & \text { p. 315-329 Página } 326\end{array}$


ardentes e brilhantes, não é luz que "alumia" como parte simbiótica e presente na natureza, mas a luz que derrete e depois se apaga, transformando tudo em cinzas e destruição.

Por esta razão, os assassinatos de Nazildo, Dilma, Claudionor, Hilton, Carlos, Alexandre e tantos outros/as que aqui não couberam não podem ser tratados como meras fatalidades, como mera expressão fenomênica da violência no espaço agrário: estão intimamente vinculados a uma lógica da colonialidade violenta que reside nos projetos de desenvolvimento, sejam eles minerários, do agronegócio, madeireiros, hidrelétricos ou outros. Trata-se, por conseguinte, de uma continuidade das formas de expansão territoriais coloniais, sendo, neste caso, a colonialidade do poder sobre os territórios o que continua substanciando esta estratégia de desenvolvimento.

É preciso compreender que a máxima da exploração de novos fundos territoriais é colonizar e que isso nunca mudou. Há, de fato, um "móvel extrativista" em atuação, no qual funções distintas se sobrepõem ao longo da história num mesmo lugar, articulando capital primário com novas frações do capital. Mudaram os termos, hoje traduzidos por "transformar", "progredir" ou "desenvolver", um eterno "vir a ser" em relação à Amazônia, mas não mudaram as expropriações. Na prática, elas se mantêm em maior ou menor intensidade, subjugando e incorporando as populações autóctones nesse processo ou, caso haja resistência, eliminando-as de modo literal. Ocorre a desagregação das relações com a terra, com a natureza, com a morada, com o trabalho e com outras relações que já estavam tecidas no território. Neste sentido, não se pode dizer que as sucessivas expropriações são fruto somente de uma ação que se resume à esfera produtiva, pois como a terra tem o caráter de sobrevivência para determinados grupos, a indisponibilidade deste bem resulta, evidentemente, numa eliminação que é também política.

A fronteira, então, configura-se como "território da morte", da desumanização, dos arcaísmos, sendo o contrário daquilo que se reproduz em seu imaginário. Se o imaginário aponta para a realização e o progresso, então os povos do campo, do cerrado e da floresta estão ainda "na porta de um futuro que nos nega seus favores" 7 , favores que nunca chegam a quem de fato é parte daquele chão.

\section{AGRADECIMENTOS}

Ao financiamento desta pesquisa através de bolsa provida pela Coordenação de Aperfeiçoamento de Pessoal de Nível Superior (CAPES).

\section{REFERÊNCIAS}

AMAZÔNIA REAL. Coordenadora do MAB é morta com requinte de crueldade no Pará. Reportagem de Moisés Sarraf, 22 de março de 2019. Disponível em: https://bit.ly/3mxLYnV.

ARBEX JR., José. "Terra sem povo", crime sem castigo. TORRES, Maurício (org.). Amazônia revelada: os descaminhos ao longo da BR-163. Brasília: CNPq, 2005, pp.21-65.

ARRIAGA RODRÍGUEZ, J. C. El concepto frontera en la geografía humana. Perspectiva Geográfica, Vol. 17 de 2012, Enero-Diciembre, pp. 71-96, 2012.

https://doi.org/10.19053/01233769.2263

BBC NEWS BRASIL. Imagens mostram avanço do garimpo ilegal na Amazônia em 2019. Por João Fellet e Camilla Costa. São Paulo e Londres, 25 de julho de 2019. Disponível em: https://www.bbc.com/portuguese/brasil-49053678.

BENEDETTI, A.. Chaves para pensar sobre fronteiras a partir de uma perspectiva geográfica. GEOUSP Espaço E Tempo (Online), 22(2), 309-328, 2018 Disponível em: https://doi.org/10.11606/issn.2179-0892.geousp.2018.133707

BRASIL DE FATO. Contag e CPT alertam para clima de guerra no Pará após mais uma execução no campo. Por Igor Carvalho, 12 de junho de 2016. Disponível em: https://bit.ly/2BTRPyQ

BRUM, Eliane. A miliciarização da Amazônia: como o crime vira lei e o criminoso "cidadão de bem" na maior floresta tropical do mundo. In: COMISSÃO PASTORAL DA TERRA. Conflitos no Campo

Brasil 2019. Goiânia: CPT Nacional, 2020, pp.105-114.

7 Em referência à canção do cantor e compositor paraibano Chico César, intitulada "Nas fronteiras do mundo" (2002).

$\begin{array}{lllll}\text { Caminhos de Geografia } & \text { Uberlândia-MG } & \text { v. 23, n. } 85 & \text { fev./2022 } & \text { p. 315-329 Página } 327\end{array}$


Brasil, construtor de ruínas: um olhar sobre o Brasil, de Lula a Bolsonaro. Porto Alegre: Arquipélago Editorial, 2019.

CASANOVA, Pablo González. Colonialismo interno (una redefinición). In: BORON, Atilio, AMADEO, Javier e GONZÁLEZ, Sabrina (orgs.) La teoría marxista hoy. CLACSO, Buenos Aires, 2006.

CARDIN, E. Laranjas e sacoleiros na tríplice fronteira: um estudo da precarização do trabalho no capital contemporâneo, Cascavel: EDUNIOESTE, 2011.

CARDOSO DE OLIVEIRA, Roberto. A noção de colonialismo interno na etnologia. Tempo Brasileiro, Rio de Janeiro, v. 4, n. 8, p. 105-112, 1966.

CATAIA, M. A relevância das fronteiras no período atual: unificação técnica e compartimentação política dos territórios. Scripta Nova. Revista Electrónica de Geografía y Ciencias Sociales. Barcelona: Universidad de Barcelona, 1 de agosto de 2007, vol. XI, núm. 245 (21). Disponível em: http://www.ub.es/geocrit/sn/sn-24521.htm.

COMISSÃO PASTORAL DA TERRA. Conflitos no campo Brasil 2018. [Coordenação: Antônio Canuto, Cássia Regina da Silva Luz, Paulo César Moreira dos Santos]. Goiânia: CPT Nacional, Brasil, 2019, 247p.

COY, M.; KLINGLER, M.; KOHLHEPP, G. De frontier até pós-frontier: regiões pioneiras no Brasil dentro do processo de transformação espaço-temporal e sócio-ecológico. Confins - Revista francobrasileira de geografia, n.30, p. 1-48, 2017. https://doi.org/10.4000/confins.11683

CPT ALTO XINGU. Nota de Repúdio pelo assassinato do companheiro Alexandre [online]. Tucumã, 21 de outubro de 2019.

DE ANGELIS, Massimo. Marx y la acumulación primitiva. El carácter continuo de los "cercamientos" capitalistas. Revista Theomai. Red Internacional de Estudios sobre Sociedad, Naturaleza y Desarrollo, Buenos Aires, núm. 26, julio-diciembre, 2012. Disponível em: https://www.redalyc.org/articulo.oa?id=12426097003.

DE OLHO NOS RURALISTAS. Mapa das Terras dos Parlamentares mostra que eles acumulam fazendas na Amazônia e no Matopiba. Publicado em 12 de maio de 2019. Disponível em: https://bit.ly/2VntMPY.

FAULHABER, Priscila. A fronteira na Antropologia Social: as diferentes faces de um problema. BIB, São Paulo, no 51, 1ํsemestre de 2001, pp.105-125.

FERNANDES, Arissane Dâmaso. A expansão da fronteira e a formação de uma ideologia no Brasil. Revista História Hoje [Revista Eletrônica de História], volume 4, no 10, pp.1-12, Agosto de 2006.

FERRARI, M. As noções de fronteira em geografia. Revista Perspectiva Geográfica, UNIOESTE V.9, N.10, pp 1-25, 2014.

GUEDES, André Dumans. Lutas por Terra e Lutas por Território. Fronteiras e Passagens nas Ciências Sociais Brasileiras. In: XV Encontro da Associação Nacional de Programas de PósGraduação e Pesquisa em Planejamento Urbano e Regional, 2013, Recife. Anais do XV Encontro Anpur, 2013.

HARVEY, David. Notas hacia una teoría del desarrollo geográfico desigual. GeoBaireS Cuadernos de Geografía. [Edição: Vicente Di Cione; Tradução: Juan Villasante y Lisa Di Cione]. UBA-FFyL, Mayo de 2007. 54p. Disponível em: https://bit.ly/3e6JFnf.

. O Novo Imperialismo. 1.ed. São Paulo: Edições Loyola, 2004.

LEVIEN, Michael. Da acumulação primitiva aos regimes de desapropriação. Sociologia \& Antropologia. Rio de janeiro, v.04, 01, p. 21 - 53, junho/ 2014. https://doi.org/10.1590/2238$38752014 \mathrm{v} 412$

MARTINS, José de Souza. Fronteira. A degradação do Outro nos confins do humano. São Paulo: Editora Hucitec, 1997.

MORAES, Antonio Carlos Robert. Território e história no Brasil. Editora Hucitec, Annablume: São Paulo, 2002. 2011. 156p.

Geografia histórica do Brasil: capitalismo, território e periferia. São Paulo: Annablume,

NOGUEIRA, R. J. B. Fronteira: espaço de referência identitária?. Ateliê Geográfico Goiânia-GO, v. 1, n. 2, p. 27-41, 2007. https://doi.org/10.5216/ag.v1i2.3013

$\begin{array}{lllll}\text { Caminhos de Geografia } & \text { Uberlândia-MG } & \text { v. 23, n. } 85 & \text { fev./2022 } & \text { p. 315-329 Página } 328\end{array}$


OLIVEIRA, Ariovaldo Umbelino de. BR-163 Cuiabá-Santarém: Geopolítica, grilagem, violência e mundialização. IN: TORRES, Maurício. Amazônia revelada: os descaminhos ao longo da BR-163. Brasília: CNPq, 2005, pp. 67-183.

OLIVEIRA, Lúcia Lippi. A conquista do espaço: sertão e fronteira no pensamento. História, Ciências, Saúde. Rio de Janeiro, volume V, p. 195-215, julho 1998. https://doi.org/10.1590/S0104$\underline{59701998000400011}$

PORTO-GONÇALVES. Carlos Walter. Amazônia, Amazônias. 2ª Ed. São Paulo: Contexto, 2008.

Violência e democracia no campo brasileiro: o que dizem os dados de 2003. Conflitos no Campo - Brasil - 2003. [Coordenação: Antonio Canuto, Cássia Regina da Silva Luz e José Batista Gonçalves Afonso]. Goiânia: CPT Nacional, Brasil, 2003, p. 9-26.

RIVERA CUSICANQUI, Silvia. Ch'ixinakax utxiwa. Una reflexion sobre practicas y discursos descolonizadores. Buenos Aires: Tinta Limón, 2010. Pinturas. 80 pp.

SANTOS, Ederson Fernando Milan dos. Capitalismo autoritário, frentes de expansão e frentes pioneiras na fronteira brasileira. In: Anais do V Simpósio Internacional Lutas Sociais na América Latina "Revoluções nas Américas: passado, presente e futuro" [ISSN 2177-9503]. V Simpósio Internacional Lutas Sociais na América Latina "Revoluções nas Américas"... Londrina, 10 a 13 de setembro de 2013, p.120-134.

SANTOS, João Vitor. Do varguismo ao lulismo e a carência de projetos políticos para o país. Entrevista especial com Alessandro Batistella. Revista IHU-online, 23 de agosto de 2018. Disponível em: https://bit.ly/3eSHW8G. Acesso em: Maio de 2021.

SAUER, Sérgio. Demanda mundial por terras: "land grabbing" ou oportunidade de negócios no Brasil?. Revista de estudos e pesquisas sobre as Américas, v. 5, no 1, 2010. https://doi.org/10.21057/repam.v4i1.3446

SILVA, Sandro; TAVARES, Giovana; SÁ, Dominichi; FRANCO, José Luiz. Fronteira, História e Natureza: a construção simbólica do Oeste Brasileiro (1930-1940). Hlb: Revista de Historia Iberoamericana, v. 7, p. 42-64, 2014.

STAVENHAGEN, Rodolfo. Clases, colonialismo y aculturación. América Latina: Revista del Centro Latinoamericano de Investigaciones en Ciencias Sociales, VI (4), Río de Janeiro, 1963.

THÉRY, Hervé. Fronteiras da Amazônia [Diálogos sobre a Amazônia na contemporaneidade: Ateliê de ideias e propostas]. YouTube: Canal Instituto Democracia e Sustentabilidade. 25 de maio de 2015 (144min). Disponível em: <https://www.youtube.com/watch?v=G4ICEUz1wTY\&t=1528s $>$. Acesso em: novembro de 2019.

. Situações da Amazônia no Brasil e no continente. Estudos Avançados, no 19 (53), pp.3749, 2005. https://doi.org/10.1590/S0103-40142005000100003

TURNER, Frederick Jackson. The Frontier in American Democracy. Nova lorque: Dove, 1996.

VELHO, Otávio Guilherme. Capitalismo autoritário e campesinato: um estudo comparativo a partir da fronteira em movimento. São Paulo - Rio de Janeiro: Centro Edelstein de Pesquisas Sociais, 1979 [2009].

WEGNER, Robert. A conquista do Oeste: a fronteira na obra de Sérgio Buarque de Holanda. Belo Horizonte: Ed. UFMG, 2000, 275p.

ZUSMAN, P. Representaciones, imaginarios y conceptos en torno a la producción material de las fronteras. Reflexiones a partir del debate Hevilla-Escamilla. Biblio 3W. Revista Bibliográfica de Geografía y Ciencias Sociales, № 149, Universidad de Barcelona, 1999.

Recebido em: 29/10/2020

Aceito para publicação em: 19/05/2021 